\title{
PRODUÇÃO DE CONHECIMENTO
}

\author{
Geraldo Antonio Bergamo* \\ Marisa ReZEnde Bernardes ${ }^{* *}$
}

RESUMO: O presente estudo trata de um esforço para, a partir do que o próprio Marx descreveu como sendo o seu método e rastreando a aplicação que ele fez, explicitar as características gerais desse método, com o fim de contribuir para que sua aplicação possa se dar para aqueles pesquisadores, do campo marxista, que têm se dedicado a investigar a educação. Disso deriva que seu objeto de estudo não tem como foco o conhecimento, mas sim a produção de conhecimento, entendida como uma particular produção que compõe a produção em geral na atual formação econômico-social. De maneira sintética, busca-se exemplificar qual seria a natureza de uma aplicação do método em ciência da educação no que concerne à produção de conhecimento na prática científica e à produção de conhecimento escolar.

Palavras-chave: Método marxista. Conhecimento. Produção de conhecimento. Produção de conhecimento escolar.

\section{KNOWLEDGE PRODUCTION}

ABSTRACT: This paper strives to explain the main features of what Marx himself described as his method, based on the very method and on how Marx applied it, so that researcher from the Marxist field who dedicate to Education may apply it. Thus, its subject is not knowledge itself, but the production of such knowledge understood as a particular production that composes the general one in the current socioeconomic formation. It tries to illustrate in a synthetic way what would be an application of the method to the Sci-

* $\quad$ Mestre em Educação Matemática pela Universidade Estadual Paulista (UNESP) e doutorando em Educação para a Ciência pela mesma Instituição. E-mail: gabergamo@travelnet.com.br

** Mestre em Educação para a Ciência pela Universidade Estadual Paulista (UNESP). E-mail: marisarb@terra.com.br

Disponível em <http://www.cedes.unicamp.br> 
Produção de conhecimento

ence of Education with regard to knowledge production in the scientific practices and schooling knowledge production.

Key words: Marxist method. Knowledge. Knowledge production. Production of schooling knowledge.

\section{Introdução}

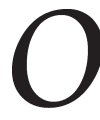

presente texto surgiu da necessidade que sentíamos de ter uma descrição suficientemente detalhada do método marxista, para poder aplicá-lo em estudos na área de educação.

$\mathrm{Na}$ "Introdução à crítica da economia política", o próprio Marx fez uma descrição geral de seu método, mas consideramos que era necessário explicitar outros pormenores que são importantes quando se está defronte a realização prática de uma investigação em educação. Dos escritos de Marx, é ainda nesse mesmo texto que se pode ter a fonte principal para desentranhar o método, haja vista que ele próprio o caracterizou como a exposição sintética de seu estudo em economia política.

Nosso trabalho consistiu em abstrair, do movimento geral das categorias realizado por Marx, quais seriam os traços essenciais da sistematização teórica realizada.

Para tanto, a leitura que Althusser faz do itinerário científico marxiano foi o guia principal, especialmente no que tange ao corte com relação ao humanismo que ele identifica na obra madura de Marx e sua descrição da chamada inversão hegeliana, inversão essa que conserva a categoria de processo sem sujeito e, ainda, ao superar o aporte hegeliano, apresenta como um traço essencial elidirem-se as categorias antropológicas na sistematização do movimento da História.

Ao nos debruçarmos sobre a tarefa, lentamente nos foi ficando claro que, se há uma unidade entre conhecimento e produção de conhecimento, faz-se necessário estabelecer as distinções interiores a essa unidade, bem como determinar qual é o pólo prevalente dessa relação. Conforme exporemos com mais detalhes, o pólo que propicia o movimento é o da produção de conhecimento, do que deriva uma prevalência da metodologia com relação à epistemologia. Portanto, se num primeiro momento trabalhávamos com a idéia de primeiro explicitar a teoria do conhecimento que se encontra implícita na obra marxiana, concluímos que a necessidade primeira se centrava em explicitar o método. 
Efetuada a abstração, julgamos conveniente esboçar uma aplicação do método em ciência da educação, apresentada de forma bastante esquemática no final deste texto. Ela se divide em duas partes, sendo a primeira uma sistematização, em nível teórico mais geral e abstrato, para a educação escolar, centrada na categoria produção de conhecimento escolar e prescindindo de categorias da psicologia e antropologia e, em seguida, uma análise da produção de conhecimento na prática científica em busca dos fenômenos das relaçóes entre os produtores de conhecimento, momento teórico esse em que os aportes antropológicos e psicológicos aparecem subordinados às categorias da ciência da história.

\section{O local e o desenvolvimento da ciência da educação}

A categoria utilizada para situar a ciência da educação é a de "continente epistemológico" (Althusser, 1975 e 1999), significando um conjunto de ciências estruturalmente de mesma natureza epistemológica, sendo uma delas o centro estruturante e as demais, regiōes que significam o desenvolvimento desse centro:

- o 1o continente epistemológico é o da matemática (já colocado sistematicamente pelos filósofos gregos) e tem como região a lógica;

- o $2^{\circ}$ continente é o da física (a partir da sistematização de Galileu e depois Newton), tendo como regiōes a química, a biologia, a geologia, enfim, as ciências da natureza;

- e o $3^{\circ}$ continente é o da história (a partir da ciência da história ou materialismo dialético, introduzido por Marx e Engels) e tem como regiōes a economia política, a geografia, a sociologia, a psicologia, a educação, enfim, as ciências humanas. Temse ainda que as categorias da economia política constituem o núcleo da ciência da história.

\section{A ciência da história}

a) Tem como pressuposto a dialética entre o movimento do pensamento e o movimento do real, o qual subsiste independentemente do pensamento (não é o pensamento que cria o 
mundo). O movimento do pensamento tem natureza especulativa/teórica que é a forma que o cérebro tem de se relacionar com o mundo, o que pressupóe que a teoria deve buscar seu critério de validade na adequação prática.

b) Ciência da história significa história das formaçôes sociais. As formações sociais significam os sucessivos modos de produção que organizam a produção e a reprodução das condições materiais de existência.

Seus conceitos fundamentais são: modo de produção, base material (que é a unidade dialética de forças produtivas e relaçôes de produção), superestrutura jurídico-política, superestrutura ideológica, classe e luta de classes, determinação em última instância (ou sobredeterminação) e autonomia relativa das esferas, ou seja, suas categorias de base são pertinentes à economia política e o movimento das categorias é estruturado pelo materialismo dialético. Formação social é a unidade dialética de base material e superestruturas jurídico-política e ideológica.

Esses conceitos ou categorias são, então, básicos para a ciência da educação, aos quais se acrescentam aqueles que são próprios dessa específica regiāo continental, como processo de ensino e aprendizagem, finalidades pedagógicas, método didático, aula etc.

\section{O objeto deste estudo: produção de conhecimento}

A partir desses pressupostos, vamos colocar neste ponto a categoria produção de conhecimento e não a categoria conhecimento como objeto principal de estudo.

Para entender o processo de produção e reprodução da existência, na atual formação econômico-social, parte-se da abstração (mas abstração com alto poder explicativo) constituída pela categoria produção em geral (que é a unidade dialética dos momentos produção-distribuição-troca-consumo). No processo de análise, vai-se deparar com produções específicas, sendo dominante a produção industrial. Daí a produção de conhecimento constituir uma esfera com autonomia relativa mas que responde à dominância da produção industrial.

Colocado o foco na produção de conhecimento, tem-se que a metodologia é dominante com relação à epistemologia (que é determi- 
nada, em última instância, por aquela), no mesmo movimento em que constituem uma unidade na diversidade.

O método da economia política (Marx in Gianotti, 1999) marxista como método-base para a ciência da educação

- A realidade, que subsiste como independente do conhecimento, é o ponto de partida da intuição e da representação, configurando uma unidade/totalidade em estado caótico.

- O ponto de partida teórico é a análise, que implica um movimento de diferenciação na unidade/totalidade e o estabelecimento de relações entre as partes. É um processo de determinação: diferenciação implicando uma hierarquia que vai no sentido de categorias mais concretas/complexas para categorias mais abstratas/simples, as quais constituem determinaçôes das mais complexas não só por diferenciações surgidas no interior daquelas, como também pelo estabelecimento de nexos causais (tem-se aqui um momento de lógica formal como caso particular da lógica dialética).

- Chegando-se às categorias mais simples/abstratas o movimento é de síntese, invertendo-se o sentido da hierarquia que agora vai delas para as mais complexas/concretas. Mas o foco do movimento não está apenas nessa inversão de sentido e sim numa sistematização presidida por relações de polaridade ou oposição, tanto entre categorias quanto oposiçōes internas a uma dada categoria. Nesse processo há o estabelecimento de mediaçôes.

Esquematicamente, há os seguintes momentos de constituição de determinações e mediações:

a) a identificação de pólos opostos: $\mathrm{A}=\mathrm{B}$, num processo de totalidade;

b) a mediação imediata de pólos opostos: A é o meio imediato de desenvolvimento de $\mathbf{B}$ e reciprocamente (1 ${ }^{\text {a }}$ negação pois $\mathbf{A}$ se nega ao desenvolver $\mathbf{B}$ e reciprocamente). Nessa unidade indissolúvel dos contrários, a ação do negativo é interna, o que se diferencia da mera oposição; 
Produção de conhecimento

c) os pólos se diferenciam por serem qualitativamente distintos e então a relação entre ambos pressupõe um "termo médio", estabelecendo outra relação de mediação. Do ponto de vista lógico é que aparece a necessidade de um terceiro termo para estabelecer relação entre pólos qualitativamente irredutíveis (essa relação implica uma segunda negação em que A se determina pela negação de $\mathbf{B}$ e reciprocamente);

d) se na lógica formal o termo médio é um invariante, definido pelos pólos, aqui se tem uma mediação externa dinâmica que se desenvolve ao longo de todo o processo;

e) a ação interna e a oposição externa do negativo caracterizam uma contradição ou unidade dialética, que se resolve num momento novo de uma unidade elevada a um nível mais alto, o qual incorpora e supera a unidade anterior. ${ }^{1}$

Completada a unidade desses dois movimentos (análise e síntese) a unidade/totalidade é agora um rico complexo de determinações e relaçóes que constituem um concreto de pensamento mais adequado para representar o real nos requisitos de descrição, explicação e predição das tendências de seu desenvolvimento.

\section{Princípios normalizadores do método}

a) Deve-se fazer uma distinção entre o método de investigação e o método de exposição da teoria, no sentido de que na investigação os dois momentos estão numa unidade em que análise e síntese se encontram em permanente intercâmbio entre si e na exposição a unidade é dada pela seqüência análise para síntese ou o inverso.

b) $\mathrm{Na}$ investigação há a necessidade de a orientação do movimento estruturar-se centralmente, tendo como centro as categorias mais ricas em determinaçôes e relações. Isso também significa que a análise é dirigida pela síntese, ou seja, caracteriza a dominância da síntese na unidade análise-síntese.

c) Isso se articula com o princípio que estabelece que o mais complexo e desenvolvido tem poder explicativo para explicar 
o menos desenvolvido/complexo, mas a recíproca não é verdadeira.

d) $\mathrm{Na}$ análise, com relação às categorias mais simples/abstratas, a estruturação também é central, devendo-se ter uma categoria simples que direcione a análise, constituindo-se numa espécie de célula-ovo que, ao desenvolver-se, dará corpo orgânico à teoria. Essa categoria nuclear direciona o movimento de ascensão do mais simples/abstrato para o mais complexo/concreto.

e) As predições da teoria vão se expressar em leis de tendência, envolvendo tendências contraditórias, mas de tal modo que uma delas é prevalente sobre a outra (caso contrário recairse-ia no relativismo). Isso pressupõe que, no movimento das categorias, as categorias A e B que expressam uma polaridade são de tal forma que um dos pólos é prevalente sobre o outro. Se a prevalência é do pólo $\mathrm{A}$, tem-se uma síntese que se articula a uma lei de tendência $A^{\prime}$ que se opõe à tendência $\mathbf{B}^{\prime}$ articulada à síntese resultante da prevalência do pólo $\mathrm{B}$. Do ponto de vista lógico, isso está em acordo com o princípio de que a possibilidade de movimento apenas se coloca se pólos opostos não forem equivalentes. Note-se que na lógica formal pólos opostos são equivalentes, o que explica sua eficácia quando se trata de organizar as teorias que dizem respeito a situações estratificadas e, nessa lógica, mediação significa tãosomente um termo médio entre os pólos opostos, o que, combinado com a equivalência dos pólos, leva a sua eficácia para exprimir leis de caráter determinista.

f) Em nível teórico mais geral, o movimento das categorias deve prescindir daquelas derivadas da biologia, psicologia e antropologia, de tal maneira que, no aspecto formal, a estrutura tenha centro na categoria processo sem sujeito, a qual vai dar estrutura geral à análise ao movimentar as categorias da economia política que se adaptem ao particular campo do conhecimento que se está investigando. Chega-se assim a um nível alto de abstração, mas uma abstração que deva fazer sentido para repor uma estrutura geral da qual derivem possibilidades de incluir os aportes biológicos, psicológicos, antropológicos etc., subordinados (desse ponto de vista teórico) à estrutura geral. ${ }^{2}$ 
Produção de conhecimento

A realização desse método sobre um discurso formal anterior, suficientemente rico em distinções e oposições, como o da economia política clássica, foi chamado por Marx de crítica. De forma mais precisa, podemos caracterizar essa reorganização do movimento das categorias de dialetização, em que elas mudam radicalmente de significado ao passarem de meras oposições para contradições.

\section{O conteúdo materialista do método}

As relaçóes lógicas descritas anteriormente podem levar a uma dialética idealista na qual há uma identificação "final" entre pólos opostos que só teria sido tornada possível pelo pensamento movendo-se por si mesmo, sendo a lógica uma espécie de substrato ou essência do pensamento.

Neste ponto é que o deslocamento do objeto ter ido da categoria conhecimento para a de produção de conhecimento vai configurar com maior precisão que se está no campo materialista.

Particularmente, o princípio da prevalência de um dos pólos opostos está articulado ao movimento do real social que se desenvolve como tendências e contratendências, sendo possível com este método obter-se uma adequada representação que descreva uma determinada correlação de forças presente numa esfera (ou no todo) social, explique esse estágio da correlação de forças e expresse a tendência dominante de seu desenvolvimento.

Também na produção de conhecimento há uma organização de produtores em um modo de produção, em que essa esfera específica tem autonomia relativa com relação à totalidade da produção.

A produção de conhecimento científico vai ter particulares instâncias e instituições sociais que a organizam, conforme se tenha, na totalidade social, diferentes modos de produção (da produção em geral). Assim, embora haja o princípio da autonomia relativa das esferas, um determinado modo de produção científico (com seu método e a sua lógica subjacente) vai encontrar-se sobredeterminado pela prática social dominante. Está-se aqui assumindo que a lógica, conforme Lenin, constitui-se como estabilização da bilionésima repetição da atividade prática do movimento do pensamento (em seu trabalho/relação de representação do real). 
Além disso, numa sociedade dividida em classes, métodos e lógicas oponentes têm como lei de tendência respectivas filiaçôes a interesses de classes antagônicas.

\section{Relaçóes entre produção de conhecimento e conhecimento e entre metodologia e epistemologia}

No desenvolvimento de uma teoria, a lógica subjacente organizadora e os dados constituem uma unidade na diversidade:

a) há uma identidade entre a lógica e os dados, no sentido de que um certo conjunto de todos os dados já é uma certa lógica organizadora, bem como de uma certa lógica (o princípio organizador) determinar o conjunto de dados correspondente;

b) um conjunto de dados é o meio imediato para se desenvolver a lógica que os sistematiza e a lógica subjacente é o meio imediato para que os dados desenvolvam um determinado significado no sistema teórico correspondente;

c) lógica e dados têm natureza qualitativa distinta e daí há a necessidade de um determinado método científico para estabelecer a relação entre ambos.

Esses três passos não se constituem como uma seqüência lógica, a não ser em termos de necessidade de exposição. No pensamento, mais propriamente, na investigação, há um constante "trânsito" entre os passos e uma dada seqüência deles aparece apenas como uma estabilização provisória do movimento.

Além do mais, esse movimento não é uma forma lógica que seria a "essência" do pensamento, ou seja, o meio no qual um suposto ser ectoplasmático, o "pensamento", teria condições de existir por si mesmo e, a partir daí, "instaurar" o mundo, o qual seria o mero resultado do movimento das categorias. Tem-se, sim, uma produção do pensamento que está articulada com a produção, mais geral, das condições e possibilidades de existência da espécie humana.

Quanto ao movimento interno de produção de um dado conhecimento, o contínuo intercâmbio entre análise e síntese pode ser expli- 
cado como um movimento entre generalidade, particularidade e singularidade (Lukács, 1967).

$\mathrm{Na}$ qualidade de finalidade, uma teoria aspira a uma identificação entre generalidade e singularidade, sendo o conceito a forma em que a generalidade determina todas as singularidades que a constituem e as determinaçôes pelas quais uma singularidade ascende à generalidade que a representa. No processo prático de elaboração teórica, o que se tem é uma sucessiva aproximação quer à generalidade, quer à singularidade, que se estabiliza provisoriamente pela mediação de particularidades, as quais são categorias por assim dizer em estado prático, que aparecem tanto numa relação em que elas surgem de diferenciações internas da generalidade, e num segundo momento podem adquirir um grau maior de concretude, caminhando para uma nova generalidade de nível superior, quanto estão em relação com singularidades, sendo um meio de estabilizar suas determinações que foram possíveis de ser explicitadas dentro de um determinado marco teórico. A estabilização provisória que se organiza centralmente pelas relaçóes entre essas categorias práticas, as particularidades, constituem, por sua vez, o recorte de representação do movimento do real que foi possível de ser realizado por uma determinada investigação.

\section{À guisa de aplicação do método}

Vejamos, com um exemplo (exposto aqui de forma apenas esquemática), como organizar uma teoria e/ou uma investigação segundo o método anteriormente descrito.

Para se estabelecer uma teoria da educação, fazemos uma distinção entre educação escolar (educação sistemática) e educação familiar, educação no processo de trabalho, educação no grupo social de referência etc. (formas não-sistemáticas de educação). Na sociedade burguesa a educação escolar encontra-se desenvolvida e é hegemônica com relação às outras formas (Saviani, 2003) e, além disso, a categoria educação escolar é um conjunto complexo de determinações e relações (note-se que nos referimos a ela como educação sistemática). Nas formas de educação que chamamos de não-sistemáticas, ou não se apresentam algumas das determinações da educação escolar, ou aquelas determinaçôes que se apresentam não aparecem de maneira plenamente desenvolvida. Tem-se daí, do ponto de vista teórico, que a educação es- 
colar pode explicar o significado da educação familiar etc., mas a recíproca não ocorre.

$\mathrm{Na}$ análise da categoria educação escolar vamos nos deparar com suas determinações expressas em categorias mais simples/abstratas, como produção de conhecimento escolar, conhecimento escolar, ensino, aprendizagem, processo de ensino e aprendizagem, conteúdos, métodos, finalidades, professor, estudante, aula, relação escola-sociedade, entre outras. Destas, a que tem maior riqueza de determinaçóes e relaçōes, constituindo-se assim no núcleo direcionador da análise, é a categoria produção de conhecimento escolar, inclusive no sentido teórico de permitir estabelecer com maior precisão os nexos entre o objeto particular deste estudo (educação escolar) com a teoria da história das formações sociais (que tem como uma de suas categorias nucleares a de modo de produção).

De início a análise vai então diferenciar a produção de conhecimento (ou saber) na prática científica da produção de conhecimento (ou saber) escolar, ao mesmo tempo em que se devem encontrar as articulações entre ambas as formas de produção (note-se que podemos encontrar sistematizações desta questão naquelas pedagogias que colocam o problema da "conversão do saber científico em saber escolar"). Isso pressupõe a diferenciação e articulação entre conhecimento da ciência de referência e conhecimento da matéria/disciplina escolar correspondente, bem como a diferenciação e articulação entre método científico e método didático (método de ensino e método de aprendizagem). Em termos de síntese, correspondentemente ao estabelecimento do método científico como mediação de dados e lógica organizadora na produção científica, vai-se ter aqui o método didático (e não o professor) como mediação de estudante e conhecimento historicamente acumulado na ciência de referência (convertido em conhecimento escolar na produção de conhecimento escolar). No mesmo movimento das categorias, há tanto uma diferenciação quanto uma articulação entre essas mediaçōes (o que tende a permitir, num estudo não-esquemático como o aqui apresentado, um maior esclarecimento das relaçôes de diferenciação/articulação entre método científico e método didático, tema esse candente nas questôes referentes à formação de professores para o ensino de ciências).

Neste contexto, a categoria estudante pressupõe um conteúdo científico escolar (idem para artístico, filosófico, da cultura erudita) 
Produção de conhecimento

historicamente acumulado e elaborado que, ao ser apropriado pelo estudante, identifica-o com o conteúdo, no mesmo movimento em que a categoria conteúdo científico escolar pressupõe um estudante que, ao constituir significados para esse conteúdo, identifica-o com o estudante (note-se que aquelas explicaçôes que partem de caracterizar o estudante com base em dados como, por exemplo, se é filho de pai alcoólatra e/ou mãe prostituta, com a inevitável conclusão de que o papel fundamental da escola é o de propiciar atividades que elevem o grau de auto-estima desse sujeito, embora não sendo elimináveis, deixam de ter, no contexto teórico aqui apresentado, nível elevado de poder explicativo).

Ainda no movimento teórico dessas categorias, o estudante é, então, o meio imediato para o desenvolvimento do conteúdo científico escolar, entendendo desenvolvimento do conteúdo como o processo de significação (constituição de significados) realizado pelo estudante, e o conteúdo é o meio imediato de desenvolvimento do estudante, entendendo seu desenvolvimento como o processo de apropriação que vai colocando o estudante em condições adequadas de integrar o conjunto de relações humanas presentes na atual formação econômico-social.

No entanto, estudante e conteúdo não se identificam imediatamente e não é tão-somente um o meio imediato para o desenvolvimento do outro. No processo de significação e apropriação há a mediação do método didático (método próprio à transmissão escolar de determinado conteúdo e método próprio à aprendizagem desse conteúdo), e o método didático vai ser tanto mais eficaz quanto mais estiver ancorado na sistematização historicamente acumulada e elaborada na prática social educativa (e não na "experiência" de tal ou qual professor e no "cotidiano" de tal ou qual estudante).

$\mathrm{Na}$ exposição seguinte seremos mais esquemáticos, pressupondo que o recurso à analogia permita ao leitor desenvolver o que será aqui apresentado.

Analogamente, e em unidade com a dialética anterior, há o movimento das categorias estudante e finalidades da educação, e a mediação do método didático vai pressupor suas relações de diferenciação/ articulação com o método de sistematização axiológico e o método da prática social política (numa sociedade dividida em classes).

No processo de significação/apropriação, a polaridade estudanteconteúdo tem como pólo prevalente o estudante quando se está tratan- 
do de explicar o processo de individuação (e não de individualização) em que a internalização de conteúdos e finalidades vai se desenvolvendo na direção de o indivíduo "inscrever-se" dominantemente em um ou outro dos pólos do antagonismo de classe, e a prevalência do pólo conteúdo vincula-se a estar se tratando de explicar o significado da cultura em formar a humanidade de sujeitos "inscritos" em tal ou qual pólo do antagonismo de classe. Isso significa que os métodos didáticos não se desenvolvem de maneira apenas interna às necessidades colocadas na esfera educativa, mas encontram-se subordinados ao metabolismo social produtor de mercadorias e disciplinador de uma força de trabalho subordinada à reprodução do capital (embora possa aparecer à consciência de determinado professor que seu esforço para melhorar seu método didático seja apenas parte de seu compromisso profissional de "cuidar bem do desenvolvimento do aprendizado de seus alunos"). Este núcleo de análise, ainda, pode ser utilizado para explicar o conteúdo das sucessivas "reformas do ensino" que se põem a partir dos órgãos governamentais, bem como o sucessivo "fracasso" destas (fracasso no que concerne a serem analisadas apenas na esfera restrita do desenvolvimento de um "bom" processo de ensino e aprendizagem, mas que ganham sentido e se apresentam como "sucesso" se forem levadas em conta suas reais finalidades de reproduzir o metabolismo social vigente).

Articulado a esses movimentos, tem-se ainda aquele das categorias professor e conteúdos/saberes profissionais (que envolvem tanto a ciência de referência quanto a ciência da educação, as práticas sociais da categoria docente nas suas lutas econômicas e as práticas sociais políticas em que a categoria se encontra subsumida à luta de classes). A mediação aqui vai ser encontrada no método de formação de professores.

A questão que agora se coloca é: Todo esse movimento se encontraria condensado em uma categoria que pudesse servir de unidade de análise, a partir da qual se poderia realizar o movimento inverso, ascendendo do simples ao complexo?

Se nesse movimento da síntese para a análise a categoria centralizadora foi a de produção de conhecimento escolar, no movimento da análise para a síntese a categoria simples/abstrata centralizadora para o estudo da educação escolar é a aula.

É na aula que o conjunto das relações produtivas gerais, como determinação em última instância, e as relações específicas de produção de 
Produção de conhecimento

conhecimento escolar se materializam em sua forma mais desenvolvida. $\mathrm{Na}$ aula, a produção e o consumo de conhecimento escolar dão-se, por assim dizer, ao mesmo tempo, esgotando-se no próprio ato de produção e consumo, o que poderia levar a crer que o produto, o conhecimento escolar, teria apenas valor de uso, subtraindo-se assim ao circuito da mercadoria. Nada mais enganoso do que essa aparência. Não se freqüenta a escola pela finalidade de se obter conhecimento em si mesmo, mas para se posicionar no mundo do trabalho, e o valor de uso do conhecimento escolar adquirido é o seu valor de troca como potenciador da mercadoria força de trabalho. Já o seu valor de troca apenas se realiza se ele for eficazmente incorporado na força de trabalho daqueles indivíduos que lograrem um emprego. No mesmo movimento, não se ensina com a finalidade de os alunos aprenderem, mas sim de potenciar a provável força de trabalho futura que está presente na sala de aula. $\mathrm{O}$ valor de uso do ensino será, então, o valor de troca como potenciador da força de trabalho. É nesse ponto que ensino e aprendizagem se identificam, e não na produção e no consumo do produto conhecimento escolar na aula. Nas escolas privadas, essa determinação das atuais relações sociais pode ser percebida de forma mais imediata, porque outras mercadorias também nelas estão presentes: as próprias aulas. Mas também no ensino público a lógica organizadora é a mesma, embora possa aparecer à consciência de determinado professor que se trata apenas de ensinar e aprender o conhecimento historicamente acumulado (e todo o séquito de sermões e dissabores com relação àqueles estudantes "indiferentes"). Note-se que a questão recorrente dos estudantes é: Professor, para que serve? Questão mais do que pertinente, pois é uma questão ligada a um juízo de realidade: Esse conhecimento tem ou não tem substância para potenciar nossa força de trabalho? Ou seja, vai nos permitir ganhar dinheiro?

No tempo da aula o ensino só vai ganhando sentido ao ir se desenvolvendo como aprendizagem de estudantes, mas aprendizagem diferenciada, que diferencie estudantes uns dos outros, ou seja, por ser essa mediação imediata da aprendizagem é que o ensino não é indiferente. Ao contrário, o ensino é diferenciador e, portanto, diferenciado nas relaçôes de sala de aula. Também a aprendizagem, por ser diferenciada, vai dando sentido e, ao desenvolver-se, vai também dando validade àquele ensino que atenda às necessidades de potenciar a força de trabalho (que, necessariamente, deve se diferenciar ao longo do proces- 
so escolar). Fora disso, há apenas o ranger de dentes dos professores que não entendem por que boa parte dos estudantes está se lixando para suas perorações. Só faria sentido um ensino cujo valor de uso fosse a aprendizagem e, reciprocamente, se a sociedade lograsse sucesso em sair fora do metabolismo destrutivo do capital, segundo princípios em que todas as atividades, inclusive as didático-pedagógicas, estariam ancoradas no objetivo de propiciar o desenvolvimento da omnilateralidade humana. ${ }^{3}$

Todavia, nas relações de sala de aula, ensino e aprendizagem têm determinações qualitativamente distintas e, portanto, só podem se dar no mesmo tempo e espaço pela mediação de um método didático. Mas métodos didáticos só têm valor se forem eficazes em realizar seu valor de uso, isto é, organizarem um ensino e uma aprendizagem que potenciem diferencialmente a força de trabalho que se encontra (socialmente falando) presente no corpo discente. Por intermédio de um conjunto complexo de práticas, as escolas privadas vão encontrando os meios de realizar essa tarefa, nas situações concretas de cada país ou território (dado que a divisão do trabalho tem determinações internacionais e, dentro de cada país, determinaçôes regionais diferenciadoras, segundo a lógica que busca a reprodução do capital em situações que sejam as mais favoráveis). Já o sistema público tem de ser cada vez mais monitorado, pois, em razão do próprio desenvolvimento das condições de reprodutibilidade do capital, tornaram-se mais complexas as tarefas sociais de reproduzir a força de trabalho. É mundial o fenômeno do esforço estatal em controlar o método didático, por meio de programas de educação continuada dos professores, controle de edição e utilização de livros e outros materiais didáticos, bem como de sistemas nacionais de avaliação. De forma esquemática, essas são determinaçôes da aula na sociedade burguesa.

Aplicado o método em sua forma desenvolvida (e não apenas esquematicamente como aqui foi feito para os propósitos e limites deste texto), aquela totalidade que inicialmente se apresentava relativamente indiferenciada e caótica ("intuitiva"), como representação do fenômeno educação escolar, passa a ter um estatuto de conhecimento sistematizado para representar o movimento real da educação escolar. Tal movimento das categorias, cuja síntese é articulada pela (categoria de) produção de conhecimento escolar, cujo processo de determinaçōes acabará dando de encontro com (a categoria) aula e cujo movimento analítico tem a aula como unidade de análise para se ascender de volta 
ao processo total da educação escolar, tem grau relativamente adequado para descrevê-lo, explicá-lo e ser um importante subsídio para orientar intervenções na prática escolar que estejam em consonância com práticas sociais educativas vinculadas (tendencialmente) a finalidades de transformação do metabolismo social atualmente vigente.

Note-se que, se neste nível teórico a mediação é o método didático, isso não elimina a mediação ser o professor.

O que aqui se tem é o processo de produção de conhecimento escolar (sobredeterminado pelo processo de produção em geral na atual formação econômico-social) significar uma organização de produtores relativamente desenvolvida, em condições de produzir e reproduzir a elaboração historicamente acumulada, teórico-prática, para constituir um processo de ensino e aprendizagem que tenha eficácia em propiciar a transmissão/apropriação de conhecimento. A sobredeterminação, significando aqui a autonomia relativa das práticas educativas, aponta no sentido de a transmissão/apropriação, mesmo quando dirigida para a maioria, ser dominada pelo processo geral de reprodução da formação econômico-social.

Neste sentido, intencionalidade, consciência e direção do processo materializam-se no método didático historicamente acumulado e não nos tantos anos de experiência de tal ou qual professor, nem na riqueza do cotidiano de tal ou qual estudante. A partir desses pressupostos é que se passará à análise do professor como mediação entre estudante e conhecimento ou, mais propriamente, mediação de um determinado corpo docente entre um corpo discente e o conhecimento historicamente acumulado que se articula a um determinado currículo escolar. Temse aqui, ainda, a consideração do corpo docente como pólo diretivo e o corpo discente como o pólo de validade de um processo educativo.

Quando se tratar de explicar a relação entre geral, particular e singular, mediação da categoria professor, intencionalidade, consciência e direção do processo, não se poderá prescindir, para sua explicação, dos aportes biológicos, psicológicos e antropológicos.

Em suma, o movimento geral das categorias que sistematizaram o estudo da educação escolar, esquematicamente aqui apresentado, ao evitar uma antropologização ou psicologização, tem o sentido de evitar recair em ilusões humanistas, que facilmente se insinuam pelos poros da teoria quando se está tratando de educação. Em contrapartida, quan- 
do se quiser utilizar a análise para explicar as relações que acontecem na sala de aula, a antropologia e a psicologia têm contribuiçóes a oferecer para a explicação dos fenômenos didático-pedagógicos.

\section{Sobre a produção de conhecimento na prática científica}

No que segue, ainda de maneira esquemática, desenvolver-se-á uma análise da produção de conhecimento na prática científica, em que as categorias psicológicas e antropológicas utilizadas se encontram subordinadas às categorias nucleares da ciência da história e, como objeto de análise, tem-se uma explicitação particular da unidade dialética de objetivo e subjetivo.

É na investigação que vão se identificar, no mesmo movimento em que se confrontam, o movimento do pensamento e o movimento do real. A contínua tarefa do investigador, de buscar adequação da teoria ao movimento real prático, tem a aparência de retirar a produção de conhecimento científico do circuito da mercadoria, por aparecer como um intenso esforço "isolado" do pesquisador sobre o seu tema (e assim aparece à consciência do pesquisador no ato da investigação). Mas isso é enganoso. $\mathrm{O}$ valor de uso da teoria é o seu valor de troca, quantitativamente determinável, pela taxa excedente de mais-valia relativa que essa teoria puder realizar nas práticas produtivas, sendo esse o seu momento de identidade com o movimento do real (o resto é a urticária do pesquisador "incompreendido", diante de um mundo que teima em se lixar para a sua produção "desinteressada").

$\mathrm{Na}$ sociedade burguesa, a mediação do método científico encontra-se articulada às determinações do próprio método, por meio de uma complexa trama de instituiçôes que vão balizando as áreas de interesse social, os temas de maior "necessidade", os raciocínios corretos, os protocolos válidos, os pareceristas com credenciais adequadas ao julgamento dos trabalhos realizados..., de tal forma que vão dando os contornos e os limites da organização dos produtores científicos. Os métodos científicos vão ganhando validade (e valor) conforme se mostrem em condições de realizar o seu valor de uso, que é o seu valor de troca, se os resultados da investigação propiciam condições de reprodução do capital (caso contrário, áreas, temas, protocolos, raciocínios... caducam na própria esfera científica). 
Produção de conhecimento

Perpassam o caminho trilhado por um pesquisador tanto situações subjetivas quanto objetivas. Caso se queira arbitrar um início para estas dificuldades, uma opção interessante são as originárias das necessidades e exigências da pesquisa acadêmica em face das reais: por um lado as necessidades e exigências das situaçôes reais, das pessoas reais (redundância útil, neste caso) e por outro aquelas da pesquisa acadêmica, que nem sempre coincidem. Muitas vezes, no fio da navalha, situa-se a ética na pesquisa.

A produção do conhecimento, segundo a perspectiva adotada, encontra-se organicamente ligada ao modo de produção que se realiza por meio das relaçóes existentes entre sua base material (unidade de forças produtivas e relações de produção) e as superestruturas (jurídico-política e ideológica). As inquietaçôes de um pesquisador, o objetivo de pesquisar, não surgem de maneira isolada, fortuita, esporádica, mas a partir de uma raiz comum, de algo que comanda, na profundeza, uma vontade fundamental de conhecimento que fala com determinação sempre maior, exigindo sempre maior precisão: dessa forma o objetivo do ato de pesquisar é sempre dado por uma perspectiva mais ampla, tornando impossível atuar isoladamente em situação de pesquisa. Porém, é nas relaçóes entre as esferas que o pesquisador encontra uma relativa autonomia, afloram as perplexidades que levam às perguntas sobre o mundo; é neste campo que a vivência que se tem do e no mundo possibilita diagnóstico e prognóstico, e principalmente aponta um motivo para o ato de pesquisar. Tem-se, portanto, que os objetivos são constituídos nas relações sociais (que historicamente se articulam em modos de produção) e os motivos são constituídos à medida que os sujeitos internalizam os objetivos e vão lhes dando significados próprios. Nessa forma de conceber a relação entre objetivo e subjetivo, a atividade de pesquisa realiza-se na coincidência do objetivo e da motivação, no processo de pesquisa que, realizando as relações do homem com o mundo, satisfazem uma necessidade especial correspondente a ele (Leontiev, 1981). Na relação (produtora de conhecimento) entre o pesquisador e o conteúdo de sua investigação, o método científico vai encarnar tanto os aspectos objetivos quanto os subjetivos, que se materializam numa determinada produção científica. Dessa forma é possível perceber que tanto o ato de pesquisar quanto o objeto de pesquisa não são neutros, e que o ofício de pesquisa é um ato político, que só pode haver certos tipos de sujeito de conhecimento, certas ordens de verdade, certos domínios de saber a par- 
tir das condições que são o solo em que se formam o sujeito, os domínios de saber e as relaçôes com a verdade.

A coexistência do individual e do coletivo propicia situações de conflito que incitam a procura de respostas para o que não se sabe ou se sabe parcialmente. Grupos de estudo, por exemplo, ao envolverem pessoas de formação diferentes, provocam um interessante movimento entre as diversas esferas tais como graduação, pós-graduação e docentes. Porém, não deve ser um tipo de relação que o meio escolar tende a sacralizar, ou seja, pessoas mais graduadas na escala acadêmica ensinando aos menos graduados: esta interação deve e pode provocar um processo de retroalimentação das pesquisas. Estes intercâmbios são coerentes com a teoria do conhecimento que vê nas lutas, no confronto de mecanismos ou realidades de natureza diversa a possibilidade de se produzir conhecimento. Os alunos da graduação, alunos de diferentes programas de pós-graduação, professores de diferentes locais e mesmo de diferentes áreas não são meros interlocutores: ao serem incorporados à paisagem intelectual transferem e obtêm informaçôes.

Pesquisar é um ato que obriga também ao envolvimento com outros ambientes de pesquisa. Este trânsito, em outros ambientes de pesquisa, não só possibilita conhecer e trocar impressões e referências bibliográficas, pessoalmente, com pessoas que têm interesses comuns como também auxilia em situações práticas, como obter cópias de materiais aos quais, por outra via, ou não se teria acesso, ou que não seriam simples de se obter. Isso se dá por intermédio de uma série de instituições e meios de circulação do conhecimento que organizam os seus produtores dentro dos marcos do, e subordinados ao, metabolismo social que tende a transformar toda produção humana em mercadorias, subordinando o valor de uso ao valor de troca. Se na sociedade burguesa, de um lado, a produçãao de conhecimento científico se desenvolveu em um nível muito superior ao dos modos de produção anteriores e goza de uma autonomia relativa como uma das esferas produtivas, por outro lado está condicionada às suas relaçóes com o valor-trabalho para a reprodução do capital. A tendência dominante é a de uma tecnologização da ciência (Antunes, 1999), que permeia a lógica das instituiçôes que organizam os produtores de conhecimento científico, os quais, portanto, não são autônomos para estabelecer uma disjunção entre a sua produção específica e as determinações, socialmente destrutivas, do capital.

Recebido em maio de 2005 e aprovado em agosto de 2005. 
Produção de conhecimento

Notas

1. O esquematismo tese-antítese-síntese é uma banalização do significado de dialética. Uma dialética que responda ao desenvolvimento teórico a partir de Hegel comporta quatro movimentos, aos quais Marx e Engels vão dar conteúdo material.

2. Se, por um lado, o mais complexo e desenvolvido explica o menos complexo, por outro lado não o substitui e, muito menos, o elimina. Esse pressuposto caminha na contramão da interpretação de Althusser, segundo a qual o corte epistemológico efetuado na ciência da história eliminaria de vez o lugar ocupado pelas categorias antropológicas.

3. Tem-se para a produção de conhecimento escolar determinações similares àquelas da subsunção da produção científica ao metabolismo do capital, conforme a apresentação que Antunes faz da discussão desse tema levada a cabo por Mészáros.

Referências bibliográficas

ANTUNES, R. Os sentidos do trabalho. São Paulo: Boitempo, 1999.

ALTHUSSER, L. Lénine et la philosophie suivi de Marx et Lenine devant Hegel. Paris: François Maspero, 1975.

ALTHUSSER, L. A querela do humanismo. Crítica marxista, São Paulo, n. 9, p. 9-51, 1999.

DUARTE, N. A anatomia do homem é a chave da anatomia do macaco: a dialética em Vigotski e em Marx e a questão do saber objetivo na educação escolar. Educação \& Sociedade, Campinas, n. 71, p. 79-115, 2000.

LEONTIEV, A.N. Uma contribuição à teoria do desenvolvimento da psique infantil. In: LeONTIEV, A.N.; LuRIA, A.R.; VIGOTSKI, L.S. Linguagem, desenvolvimento e aprendizagem. São Paulo: Cone, 1981. p. 59-83.

LUKÁCS, G. La categoria de la particularidad. In: LUKÁCS, G. Estética. Barcelona: Grijalbo, 1967. v.3, p. 199-275.

MARX, K. Introdução [à crítica da economia política]. In: GianotTI, J.A. (Org). Marx. São Paulo: Nova Cultural, 1999. p. 25-48.

MARX, K. O capital. Lisboa: Avante, 1990. Livro primeiro, t.1.

SAVIANI, D. A pedagogia histórico-crítica e a educação escolar. In: SaVIani, D. Pedagogia histórico-crítica: primeiras aproximações. Campinas: Autores Associados, 2003. p. 87-103. 